\title{
Fatores que influenciam na escolha da via de parto cirúrgica: uma revisão bibliográfica*
}

\author{
Factors that influence the choice by \\ surgical delivery: a literature review
}

Tatiane Abud Pimentel ${ }^{1}$ Eduardo Cyrino Oliveira-Filho ${ }^{2}$
Recebido em: 08/08/2016. Aprovado em: 05/10/2016.

1 Graduada em Enfermagem pelo Centro Universitário de Brasília (UniCEUB), Brasília-DF. E-mail: ttabud@gmail.com.

2 Doutor em Saúde Pública e Professor do Centro Universitário de Brasília (UniCEUB), Brasília-DF.E-mail: eduardo.cyrino@uniceub.br.

\section{Resumo}

Nos últimos anos, observou-se um considerável aumento do parto cirúrgico. Dados do Ministério da Saúde afirmam que $88 \%$ dos bebês que nascem nos hospitais privados no Brasil são por cirurgia e no setor público chega a $40 \%$, um número elevado ante os $15 \%$ recomendados pela Organização Mundial da Saúde (OMS). Diante disso, esse trabalho propôs distinguir quais os fatores que influenciam na escolha da via de parto. Trata-se de um estudo de revisão narrativa da literatura científica nacional e internacional, consultadas nas bases de dados LILACS, Scielo, e PubMed. Concluiu-se que muitos são os fatores que influenciam o comportamento materno para a escolha por determinada via de parto, destacando-se o processo doloroso do parto, o desinteresse do profissional pelo parto normal, e a própria estrutura do sistema de saúde. Ressalta-se a relevância do pré-natal com ações voltadas para a promoção do parto humanizado.

Palavras-chave: Parto. Cesárea. Obstétrico. Trabalho de parto. Autonomia pessoal.

\begin{abstract}
Over recent years, it has been observed a large increase of cesarean delivery. Brazilian Ministry says that $88 \%$ of babies who are born in private hospitals in Brazil are by surgery, and in public sector reaches $40 \%$, a large number compared to the $15 \%$ recommended by the World Health Organization (WHO). Therefore, this academic study has proposed distinguish which the factors that influence in choice of delivery route. It is a study from a narrative review of national and international literature, artworks were consulted indexed in databases like LILACS, Scielo and PubMed. So it is concluded that the maternal behaviors are influenced by several factors with regard to preference for any delivery route, stands out among them the painful process of childbirth, the professional disinterest for vaginal delivery and the health system itself. It emphasizes the relevance to take the prenatal care with actions that promote the humanized delivery.
\end{abstract}

Keywords: Delivery. Cesarean delivery. Obstetric. Personal Autonomy. 


\section{Introdução}

Por longo tempo o parto domiciliar não intervencionista era considerado uma prática comum para as sociedades, e só a partir do século XX, a assistência cirúrgica ao parto tornou-se popular (JONES, 2004). Antes, o parto era considerado um processo fisiológico, mas o desenvolvimento da medicina levou o ato de parir a ser, predominantemente, hospitalizado, necessitando de amparo médico, tratamento medicamentoso e adjutório cirúrgico (CRIZÓSTOMO; NERY; LUZ, 2007).

Nos últimos anos, notou-se um considerável e progressivo aumento da frequência das cesáreas. Dados do Ministério da Saúde (MS) apontam que quase 80\% das mulheres que chegam ao pré-natal preferem a via de parto vaginal, mas apenas $20 \%$ dessas mulheres têm seus filhos por essa via. Essa mudança não pode ser explicada pelo surgimento de problemas e complicações em todos os casos (AGENCIA NACIONAL DE SAÚDE SUPLEMENTAR, 2014). Convém salientar que inquéritos realizados por estudos brasileiros revelaram que a preferência da maioria das mulheres, tanto das gestantes quanto das não gestantes, é o parto normal (BARBOSA et al., 2003; LEE; KHANG; LEE, 2004). A preferência pelo parto abdominal ocorre em uma minoria e está relacionada a fatores entre os quais citam-se: o desejo pela laqueadura após cirurgia e a tocofobia (GAMBLE; CREEDY, 2000; PANG et al., 2008; HOFBERG, 2000).

Eito a esse contexto observa-se alguns dados alarmantes, $88 \%$ dos bebês que nascem nos hospitais privados são por via cirúrgica, e que o percentual de cesáreas programadas e sem indicação clínica é altíssimo, alcança de $20 \%$ a $25 \%$ dos partos cirúrgicos. No setor público, esse índice é menor, corresponde a $40 \%$ dos partos, ainda assim é um número muito alto ante os $15 \%$ recomendados pela Organização Mundial da Saúde (OMS) (AGENCIA NACIONAL DE SAÚDE SUPLEMENTAR, 2013). Nessa senda certifica-se que o número de bebês brasileiros que nasceram por meio de cesariana ultrapassou o número dos bebês que vêm ao mundo pela via natural e hoje $52 \%$ dos 3 milhões de partos feitos anualmente são cesáreos (LEAL, 2014).

A posição ocupada pelo Brasil, atualmente, como um dos países com as maiores taxas de cirurgias cesarianas é reflexo do modelo intervencionista, em que o processo de medicalização do corpo feminino leva à banalização da parturição cirúrgica e o pouco conhecimento da de decisão da via de parto intensifica esse fato insustentável (AGENCIA NACIONAL DE SAÚDE SUPLEMENTAR, 2014). Faundes et al. (2004) relatam sobre a opinião das mulheres e médicos brasileiros em relação à preferência pela via de parto e conclui que a principal causa do aumento na taxa de cesárea é o desrespeito dos desejos das mulheres por parte dos médicos. No trabalho indaga ainda: "Como explicar esse abismo entre a declaração das mulheres e a percepção dos médicos acerca do que pensam suas pacientes?".

É inquestionável que a indicação de cirurgia é atribuição dos médicos, mas até que ponto as mulheres não foram involuntariamente cúmplices por absoluto desconhecimento de como seu corpo funciona? Ou pela tendência do aconselhamento profissional durante o acompanhamento pré-natal? Ou por terem embarcado na 'moda' de que cesárea é mais prático, não requer preparação, é possível agendar, e outras 'vantagens'? (DUARTE; DINIZ, 2004). Nesse embasamento torna-se, portanto, necessário investigar as reais causas que levam a decisão acerca da via de parto, uma vez que, essa escolha influencia diretamente ao aumento das taxas de parto cesáreo, posto que, com o conhecimento desses fatores, poderão ser desenvolvidas estratégias específicas que modifiquem essa tendência (ALMEIDA et al., 2008).

Diante disso, esse trabalho propôs distinguir quais os fatores que influenciam na escolha da via de parto, o modelo intervencionista e institucionalizado ou o modelo humanizado, pois acredita-se que a expectativa das mulheres a respeito da escolha do tipo de parto tem relação direta com o conhecimento das mesmas sobre o assunto (OLIVEIRA et al., 2002; SEIBERTH et al., 2005).

\section{Metodologia}

Para Lima e Mioto (2007), a revisão bibliográfica constitui um método criterioso que deve seguir métodos preestabelecidos para chegar na síntese de vários estudos traduzindo uma conclusão geral de um determinado assunto. Em vista disso, esse estudo foi desenvolvido a partir de pesquisa e revisão narrativa da literatura científica nacional e internacional, tendo como eixo condutor a evolução histórica do conceito de assistência ao parto. Segundo Rother (2007) a revisão narrativa constitui-se de artigos de ampla abordagem e apropriados para descrever e discutir um determinado tema sob o ponto de vista teórico ou contextual. 
Esse tipo de revisão permite uma análise da literatura publicada na ótica e na interpretação crítica pessoal do pesquisador (BERNARDO; NOBRE; JANETE, 2004).

Para ordenação desse estudo, foram consultadas obras indexadas nas bases de dados LILACS, SciELO, e PubMed. A escolha por essas bases de dados ocorreu devido à sua amplitude e relevância ao congregar um número grande de revistas científicas na área da saúde. Utilizaram-se como axe de pesquisa os seguintes descritores: Parto; Cesáreo; Obstétrico; Trabalho de parto, assim como as mesmas palavras no idioma inglês e espanhol. Foram localizados 614 artigos científicos, no período de agosto 2014 a meados de maio 2015. Apenas 65 atenderam aos critérios de inclusão e estrutura proposta para elaboração dessa obra, critérios tais como: artigos que estavam disponíveis, gratuitamente, nas bases de dados, os disponíveis para leitura na íntegra, e aqueles que se adequavam ao tema proposto.

Essa pesquisa bibliográfica concentrou-se em artigos de periódicos científicos, livros, manuais e documentos oficiais que abarcam os períodos entre 2001 a 2015, exceto os livros utilizados para definições de conceitos e tópicos do trabalho. Foi realizado, também, a busca setorial direta na biblioteca do Centro Universitário de Brasília - UniCEUB, localizada em Brasília, Distrito Federal. Por fim, foi construída uma análise explicativa e reflexiva por meio da interpretação dos conceitos trazidos pelos autores buscando responder ao objetivo proposto por essa obra.

\section{Desenvolvimento}

\subsection{A evolução do parto ao longo do tempo}

A gestação representa um período particular na vida de uma mulher, suas angústias e seus medos se misturam com a alegria de tornar-se mãe e parte desses sentimentos é causada pelas preocupações quanto ao momento do parto (TEDESCO, 2004). O parto é visto como um processo psicossomático, no qual as escolhas das grávidas estão relacionados não só com a própria evolução da gestação, mas também com o nível de informação da mulher, seu histórico pessoal, e principalmente a influência do profissional de saúde a respeito da decisão na hora de parir (HADDAD; CECATTI, 2011).

No passado o atendimento durante o parto era bem diferente, era um acontecimento comum, que ocorria em ambiente domiciliar. Era um evento esperado do ciclo de vida da mulher vivenciado em caráter privado, realizado por mulheres de confiança das gestantes e dos familiares, que possuíam experiência reconhecida na comunidade, essas parteiras contavam com conhecimentos empíricos, transferidos de geração em geração. Acreditava-se que elas tivessem soberania sobre os mecanismos da reprodução (SOUZA, 2005). Para as parteiras, a parturição era um processo natural onde detinham o domínio do procedimento adquirido apenas pela prática, elas não somente auxiliavam as parturientes, mas também dava-lhes confiança, apoio emocional e espiritual, como verdadeiras benzedeiras realizavam rezas, poções consideradas mágicas e prodigiosas transformando a atmosfera do ambiente em um clima favorável ao nascimento, tornando o parto mais agradável (SEIBERT et al., 2005).

Nesse sentido, observa-se que, mesmo com uma cultura predominantemente patriarcal, as sociedades antigas tinham o parto como ato exclusivo do universo feminino, o partejar acontecia entre parteiras e parturientes, algo entre damas, como um momento em que elas eram detentoras de sabedoria, de autonomia, e de poder (JONES, 2004). Essa situação de exclusão refletiu em um atraso no desenvolvimento da medicina relacionado ao cuidado da mulher, pois ao contrário dos padrões culturais da época esse período está marcado por uma pequena participação masculina no cuidado à mulher (MALDONADO et al., 2002). De acordo com Carvalho (2002), no século XVI, o assunto das senhoras chamou a atenção da ciência que era exercida em sua totalidade pelo sexo masculino, mesmo sendo barrados por ordem moral nos aposentos femininos, os homens começaram a se envolver no ato de parir movidos por curiosidade e interesse científico.

Em meio a esse contexto de parturição, aos poucos a presença masculina vai tomando espaço na hora do parto, e os ideais médicos foram tomando o cenário e os partos deixaram de ser realizados pelas doulas e passaram a ser realizados pelos obstetras (REZENDE, 2010). Esses homens trouxeram novos paradigmas atraindo, assim, as parturientes para seus consultórios, disseminando a visão de que as parteiras como acompanhantes do parto deixou de ser coisa da elite, e que sua presença era essencial no quarto (TORNQUIST, 2002).

Diniz e Chacham (2005) afirmam que a mudança no processo do parto não foi apenas na assistência, mas também na ideologia, pois o modelo de cooperação médica quebrou com os paradigmas impostos pela Igreja 
Católica. Acreditava-se que a mulher deveria sofrer durante o trabalho de parto como consequência dos atos femininos nos primórdios da humanidade, destinava-se a elas a culpa pelo pecado original e, portanto, o parto deveria ocorrer sem apoio ou alívio dos riscos e dores (SCHMIDT; PICCOLOTO; MULLER, 2005).

Como expressão concreta dessa mudança de intervenção feminina para a masculina ao pé do leito, pode-se citar a criação do fórceps, esse mecanismo veio combater os perigos do trajeto transpélvico e o desenvolvimento dessa técnica quebrou com as limitações naturais existentes e muniram os doutores de novos conhecimentos e instrumentos. Esse episódio levou a um declínio na profissão das parteiras, permitindo e substituindo, enfim, o arquétipo não-intervencionista pelo parto controlado pelo homem (MEDINA, 2005).

Para Jones (2004) o avanço do capitalismo industrial alavancou com esse monopólio dos médicos, pois as doulas não tinham acesso à universidade e à teoria, e, assim, foram aos poucos se tornando subordinadas aos cirurgiões e físicos, e gradualmente se afastaram das práticas obstétricas. Esse aprimoramento do saber médico, reduziu o índice de mortalidade materna, o que contribuiu para a aceitação da hospitalização perante a sociedade, afinal ter seus filhos em clínicas passou a parecer mais seguro para as mulheres (VIEIRA, 2002). O evento fisiológico deixou de ser cultural para se tornar um acontecimento médico (TEIXEIRA; PEREIRA, 2006).

Em 1950 o ideário do parto sem dor atingiu sua maior popularidade e, com a descoberta do mecanismo da ovulação, houve, então, uma transformação do atendimento ao parto, necessitando, sem exceção, da intervenção médica. Essa situação foi responsável pelo estabelecimento da Obstetrícia como saber científico atribuindo ao médico poder exclusivo no atendimento à mulher $\mathrm{e}$ ao parto (MELO, 2003). A primazia da tecnologia e das intervenções tomou conta do evento do nascimento, e a parturiente escolhe um novo mentor para acompanhá-la, consolidando algo que vinha mudando: a assistência durante o parto (CASTRO; CLAPIS, 2005) deslocando da mulher o papel de protagonista e trazendo como atores principais do parto os médicos e seus instrumentos (JONES, 2004).

Nesse mesmo decurso as mulheres de classe mais alta tinham três razões que pesavam na escolha do parto: não sentir a dor do parto, não correr mais riscos, e o fato de parir com a assistência de um médico significar maior poder aquisitivo de seus maridos (SANTOS, 1947). Com isso, a estabilização do processo de medicalização e hospitalização do parto aconteceu em meados do século $\mathrm{XX}$, juntamente ao surgimento das grandes metrópoles e a criação de hospitais, marcando o fim da feminilização do parto. Atualmente, ocorre um predomínio do parto hospitalar marcado por intervenções cirúrgicas e episiotomias desnecessárias, mas quais são as reais razões que levam essas mulheres ao Centro Cirúrgico? (RATTNER, 2009).

\subsection{A decisão da via de parto}

$\mathrm{Na}$ verdade muitos são os fatores que influenciam o comportamento materno em relação à preferência por determinada via de parto, tais como: suas crenças, suas expectativas particulares, o processo de informações que chegam até as gestantes, a postura do profissional em tendenciar à parturiente, o desrespeito à sua autonomia e o próprio sistema de saúde (FREITAS; SAKAE; JACOMINO, 2008). Prontamente, as páginas a seguir trazem cada um desses fatores tratados detalhadamente.

\subsubsection{Vivência do processo doloroso}

Diniz e Chacham (2002) afirma que um fator relevante para a escolha da mulher é o aspecto psicológico na vivência da dor. Partindo-se do princípio de que, por ser um processo fisiológico, o parto não deveria causar dor, e que essa dor ocorre devido ao medo que ativa o sistema nervoso autônomo gerando estímulos que são interpretados na área talâmica como dolorosos, a mulher escolhe a via de parto cirúrgica. Floyd (2004), em seu estudo, afirma que o medo da imprevisibilidade do parto vaginal e as consequências de um parto vaginal demorado são citados por médicos como razões pelas quais as mulheres preferem cesáreas.

Nesse mesmo contexto de dor do parto, observa-se que a dor também está relacionada à ansiedade, contudo seu padecimento tem uma finalidade e o bebê aparece para justificá-lo. A dor representa um importante sinal do início do trabalho de parto tendo como principal componente a contração uterina associada a dilatação do colo uterino, a distensão das fibras uterinas, a distensão do canal de parto, a tração de anexos e peritônio, a pressão na uretra, na bexiga e outras em estruturas pélvicas, além da pressão sobre as raízes do plexo lombo-sacro. Ao final toda essa dor se encerra com a chegada do bebê, recompensando a mãe pelo esforço, já no parto cesáreo, seu protagonismo fica anulado (REZENDE, 2010; LOPES et al., 2005). Nesse sentido, ela norteia também a evolução 
fisiológica do trabalho de parto à medida que mantém um padrão de duração, intensidade e frequência rítmica ao longo do processo (ALMEIDA et al., 2005).

Destarte alguns dados são considerados surpreendentes, $75,5 \%$ das gestantes referem temer a dor e o sofrimento durante o parto vaginal, um elevado percentual visto que a medicina já dispõe de recursos analgésicos e de métodos não farmacológicos para alívio da dor, métodos esses como as técnicas de relaxamento, não restrição ao leito, presença de um acompanhante, permanência da posição de escolha da gestante durante o período expulsivo, enfim, vários meios que favorecem um parto mais agradável, porém o que parece ser a base do medo relacionado ao parto vaginal não é a falta de informação sobre como se preparar para esse tipo de parto, mas os problemas reais enfrentados por mulheres de diferentes classes sociais, sobre a qualidade do atendimento fornecido que chega a ser precária por distanciar e muito desse parto assistido e humanizado (BARBOSA et al., 2003; DIAS; PEREIRA, 2008). A grande maioria dos hospitais não dispõe de técnicas específicas para redução da dor, no máximo incentivam um acompanhante que esteja presente durante o trabalho de parto e a não restrição ao leito (IORRA et al., 2011).

De acordo com o Ministério da Saúde (MS) (2005), em uma cesariana feita pelo SUS, a mulher tem direito a contar com o anestesista de plantão, sala de cirurgia exclusiva para a cirurgia, e acompanhamento beira leito de uma equipe preparada para intercorrências, já no caso do parto normal o MS recomenda que, antes de ofertar uma analgesia de parto, o hospital deve ofertar os métodos não farmacológicos de alívio da dor, que oferecem menos riscos e podem resolver o problema da sensibilidade à algia sem os riscos da analgesia. Esses métodos incluem apoio contínuo, liberdade de movimentação, acesso à água (como chuveiro e banheira), acesso à escada de Ling, ao cavalinho e banquinho que são instrumentos da fisioterapia para adotar outras posições para o parto normal, além do apoio pela doula, a ambiência da maternidade e a privacidade, métodos presentes, apenas, nas Casas de Partos que são raras no país (BRASIL, 2014).

Nesse embasamento cita-se que a dor aguda, sem nada para amenizá-la, faz com que muitas mulheres passem por experiências traumáticas, ampliando a crença de que esse tipo de parto gera dores insuportáveis e que, por isso, a cesárea seria uma melhor opção (FAISAL-CURY; MENEZES, 2006). Segundo Lessa (2003) muitas mulhe- res querem cesárea para evitar a dor do parto, mas essas mulheres esquecem da dor no pós-parto, que geram dores com níveis duas vezes maiores nas cicatrizes.

\subsubsection{Questões financeiras}

Inicialmente, uma criança nascia com a enfermeira e o obstetra supervisionava, ele era chamado apenas se houvesse alguma intercorrência, mas com a criação de instâncias do INPS (Instituto Nacional de Previdência Social) as regras mudaram e o médico passou a precisar estar sempre na sala de parto, para receber, os mesmos deveriam participar efetivamente do parto (TRINDADE, 2015). Assim, nos anos 70, com a epidemia de cesarianas, o quadro começou a mudar, pois os médicos e os hospitais recebiam pagamento maior do sistema de seguridade social por parto cirúrgico do que por parto vaginal, visto que era vendida associada à esterilização definitiva, a laqueadura das trompas, o que parece ter contribuído para seu uso mais frequente (SILVEIRA et al., 2008).

A partir de 1980, em reação a essa tendência, instituiu-se uma forma de pagamento igual para todos os tipos de parto, mas tal política produziu um arrefecimento apenas temporário no crescimento do número de cesarianas, pois ao agendar o parto, a quantidade de crianças que nascem por via cirúrgica pode ser bem maior, levando o cirurgião a receber mais em um curto período de tempo devido a relativa praticidade do procedimento cirúrgico que não dura mais de duas horas (POTTER et al., 2009). Outras políticas governamentais foram adotadas numa tentativa de controle do aumento de partos cirúrgicos; em 1998, o SUS estabeleceu um limite de 40\% para a proporção de partos por cesariana que seriam pagos às instituições, e em 2000 esse limite foi reduzido até 30\% (BRASIL, 2001).

Outro fator é o interesse dos hospitais privados que recebem mais por procedimento cirúrgico. Em uma rede pública o obstetra ganha mais pelo parto normal, já na rede privada um pouco a mais pelo parto cesáreo, a diferença de valores é mínima, um profissional recebe quase a mesma coisa para fazer uma cesárea que dura cerca de 3 horas, enquanto no parto normal essa assistência pode muito bem passar de 12 horas, intensificando esse tipo de parto, pois o que faz o lucro das maternidades privadas é o agendamento prévio das cesarianas, podendo maximizar o uso dos leitos, afinal o parto normal ocupa salas e assistência por muito tempo, tem pior remuneração pelos planos de saúde e é necessário que o hospital tenha vários leitos disponíveis, aguardando mulheres que 
podem ou não entrar em trabalho de parto, o fato é que os hospitais privados não veem qualquer razão para saírem da zona de conforto dos $90 \%$ de cesarianas (BARBA; BARIFOUSE, 2015; BRASIL, 2005; PINTO, 2006).

\subsubsection{Desvalorização dos demais profissionais}

As mudanças no INPS incentivaram a presença constante dos ginecologistas durante todo o parto e acabaram desvalorizando os demais profissionais como as parteiras, doulas e enfermeiras especializadas (BARBA; BARIFOUSE, 2015). E, ainda hoje, na grande maioria dos hospitais, não há uma equipe obstétrica transdisciplinar com enfermeira obstetra, e anestesistas trabalhando juntos para auxiliar o parto normal, e muito menos há enfermeiros obstetras atuando como agentes promotor do parto normal sem riscos, mesmo aqueles partos comprovados pelo partograma que poderiam vir por via natural tranquilamente, menos ainda há anestesistas de plantão por 24 horas que poderiam amenizar as algias dos partos vaginais, sendo, esses profissionais, chamados apenas em urgências (FREBASGO, 2015; MARTINS et al., 2005).

São raríssimas as organizações que mantêm outro profissional como atuante na hora do parto e a Casa de Parto é uma das poucas opções apropriadas para materializar o cuidado integral à mulher parturiente e seu familiar por um outro profissional que não seja o cirurgião obstetra, esse sistema preconiza à atuação autônoma do enfermeiro obstétrico, e proporciona uma assistência humanizada à mulher no ciclo gravídico-puerperal (HOGA, 2004).

\subsubsection{Informações e autonomia da gestante}

A necessidade de permitir que as mulheres escolham sua forma de parir foi mencionada na II Conferência Internacional de Promoção da Saúde (1988) e deu origem à Declaração de Adelaide. Esse documento propôs a criação de políticas públicas voltadas para a prática de parto baseada nas preferências e necessidades das mulheres, evidenciando, assim, a importância de deixar com que elas protagonizem o seu próprio parto (MEDEIROS; SANTOS; SILVA, 2008). Nesse mesmo sentido, o respeito a individualidade e a opinião da gestante e dos seus familiares são apontados como meios de influenciar na decisão da via de parto (ALMEIDA, 2008). Segundo Castro e Clapis (2005), o direito à escolha sobre a forma de dar a luz constitui, na área da saúde, um direito humano e um direito reprodutivo, apontado em vários instrumentos legais nacionais e internacionais, e o desrespeito a essa au- tonomia é um dos gestores negativos para a banalização do trajeto do nascimento de forma cirúrgica.

O Programa de Humanização do Pré-natal e Nascimento, instituído pelo Ministério da Saúde vem corroborar essa visão lançada em 1988, e traz como princípio o direito da gestante a um atendimento digno e de qualidade, realizado de forma humanizada e segura no decorrer da gestação, parto e puerpério (BRASIL, 2005). Contudo, é importante ressaltar que, sem a devolução do protagonismo para a mulher, não existe humanização do nascimento. Enquanto elas não puderem escolher, livremente, a posição para parir, sua companhia, o local do nascimento e suas inúmeras vontades, apenas será reproduzida uma história de abusos e interferências desnecessárias, que não procede num mundo que se propõe democrático e igualitário (JONES, 2004).

Paralelamente a isso, à opção das gestantes livre e autônoma em grandes centros urbanos está relacionada com o acesso as informações que em geral não são acessíveis à maioria das mulheres. Possuir acesso à internet, TV por assinatura, vídeos, livros e artigos que abordassem a temática parece ter grande influência na opção da mulher e sua família pelo parto domiciliar planejado. Quanto maior o nível de informação, mais autonomia a mulher têm na decisão do tipo de parto que prefere (FAISAL-CURY; MENEZES, 2006; LESSA, 2003).

Outro fator é o profissional de saúde como formador de opinião, pois as expectativas da mulher quanto à via de parto são consequência de como as informações estão disponíveis ou são acessíveis a ela. Nesse sentido, a orientação no pré-natal tem alto potencial educativo, visto que a gestante passa a conhecer as alternativas de assistência em várias situações de trabalho de parto (ALMEIDA, 2008). Oliveira et al. (2002) atestam que a troca de conhecimentos durante a realização do pré-natal não deve ter somente o intuito de informar às gestantes, mas também deve ser um meio de interação entre o profissional e a cliente, possibilitando o esclarecimento de dúvidas, reduzindo, assim, a ansiedade das mulheres em relação ao momento do parto e ao período gestacional.

Alinhadamente a esse assunto, Ferrari (2014) afirma que a autonomia pressupõe o direito de escolher com base na informação transmitida de forma transparente por profissionais responsáveis e comprometidos, atentos para a obrigação ética de tornar as gestantes competentes para uma escolha. $\mathrm{O}$ fornecimento de informações às 
mulheres, antes e durante a gestação, deve ser um caminho a ser trilhado na tentativa de reverter esse quadro do número de cesáreas em excesso (FAUNDES, 2004).

\subsubsection{A falta de interesse do profissional de saúde pelo parto normal e sua conduta intervencion- ista}

Dias e Santos (2005) enfocam que três em cada quatro das primíparas no setor privado e oito em cada dez no setor público que realizaram cesarianas gostariam de ter tido partos vaginais, essa informação sugere que essa cirurgia esteja sendo praticada com falta de critérios e a conduta intervencionista do médico parece corroborar com o acréscimo do número de partos cirúrgicos (DAVIM; MENEZES, 2001). Essa conduta intervencionista é reforçada com todo o quadro deficiente encontrado pelos ginecologistas nas instituições em gerais como a má remuneração, equipe auxiliar falha, faculdades que preparam pouco e que são centradas no curativismo e a judicialização da medicina, assim muitos médicos acabam se convencendo de que a cesariana é a melhor opção e adotam esse tipo de parto de forma rotineira e indiscriminada (MARTINS et al., 2005).

Com base nessas considerações, norteia-se que esse modelo médico-intervencionista traz como efeito a realização cada vez menor de partos normais, assim há menos chances de treinar os novos médicos com as técnicas necessárias, levando-os a não se sentirem habilitados a fazer esse tipo de parto, e a crença de que a cesárea é a opção válida não apenas para casos de emergência é reforçada em faculdades. A judicialização da medicina, supracitada aguça mais esse medo do obstetra, pois esse preceito responsabiliza o médico por qualquer coisa que acontece durante um procedimento, então, em situações de risco, ele opta pela cesárea, afinal de contas, em caso de fatalidades ou complicações ele será questionado pelo seu atendimento, gerando um medo nos médicos em tentar o parto normal (ESPINDULA, 2013).

Moraes (2001) traz em seu estudo outro ponto inquestionável, a conveniência médica, tal feito tem como característica a adoção de rotinas rígidas que levam à despersonalização das gestantes e à supervalorização da tecnologia em prol da comodidade. Afirma, ainda, que são realizados partos por conveniência dos envolvidos no processo como os hospitais, a equipe médica, ou mesmo a própria mulher grávida, independente da urgência obstétrica. Victora (2011) corroboram com a afirmação de que os partos cesáreos são realizadas com mais frequências em horários diurnos e em dias úteis, o que sugere que esta forma de parto é conveniência para o profissional.

Nessa mesma direção, Faundes (2004) alega que a agenda do médico é fator decisivo para a indicação de cesarianas e afirma que, com o aparecimento da ultrassonografia, ficou mais fácil para marcar a cesariana "Porque fazer o parto normal no domingo, se posso fazer uma cesariana na sexta-feira?". A ultrassonografia é um recurso que permite, cada vez mais, estimar com rigorosa precisão a maturidade fetal, e os novos aparelhos permitem avaliar o feto sob várias dimensões, levando o obstetra a confiar no agendamento premeditado (MORAES, 2001). $\mathrm{O}$ atual ministro da saúde, Arthur Chioro, em entrevista à Folha de São Paulo (2015, p. 7) enfatizou:

Não podemos aceitar que as cesarianas sejam realizadas em função do poder econômico ou por comodidade. Não há justificativa de nenhuma ordem financeira, técnica, e científica que possa continuar dando validade a essa taxa alta de cesáreas na saúde suplementar.

Essa opinião é reforçada pelo estudo da Fiocruz (LEAL, 2014) que apontou o peso da opinião médica e a sua falta de interesse pelo parto normal como motivos da desinformação das mães e pais sobre o tema. Ressalta, ainda, que esse processo de tomada de decisão pelo tipo de parto se dá numa relação de poder que se estabelece no diálogo entre o médico e a mulher, e que, muitas vezes, inibe qualquer questionamento da decisão do profissional, influenciando, e muito, a opinião pública, colaborando para a epidemia da cesárea.

\subsubsection{A chance da esterilização cirúrgica}

Outro fator para aumentar a incidência de cesarianas é a possibilidade de associá-las à esterilização cirúrgica (BEHAGUE; BARROS, 2002). Torna-se necessário acrescentar também que, especialmente no interior do Brasil, é típico que, nos períodos que antecedem as eleições, ocorra uma verdadeira pandemia de laqueaduras (FERRARI, 2014).

Com relação a esse desejo de laqueadura, pode-se citar que essa é uma das principais razões para a solicitação de parto cesáreo na rede pública, principalmente em cidades interioranas, e acredita-se que só com um programa de planejamento familiar efetivo, com o oferecimento e acesso a todos os métodos contraceptivos, é que se conseguirá quebrar a associação nociva "cesárea-laqueadura", pois a escolha da laqueadura como método contraceptivo decorre das dificuldades que as mulheres experimentam 
para a obtenção de outros métodos como a pílula ou o dispositivo intrauterino (DIU), principalmente nas áreas rurais do país (BARBOSA et al., 2003; FAUNDES, 2004).

\subsection{Perspectivas futuras}

Nos últimos 30 anos, o Brasil avançou muito na melhoria da atenção ao parto e ao nascimento, isso é fruto de uma série de iniciativas do governo e da sociedade. Um dos seus esforços se dedica na implementação de ações no sentido de melhorar e incentivar o parto normal, como a abertura de Casas de Parto que permitem a mulher parir assistidas por enfermeiras obstétricas num ambiente semelhante ao domicílio, local este, que, além do acompanhante, permite privacidade, liberdade, conforto e afetividade (BRASIL, 2011).

Nesse mesmo sentido, a Agência Nacional de Vigilância Sanitária (ANVISA) tem atuado, sempre, com o intuito de tornar o parto mais humanizado. Recentemente, a ANVISA reuniu uma série de normas a serem cobradas dos hospitais públicos e particulares, regras que promovem mudanças na rotina da maternidade, dentre elas cabe ressaltar a garantia das mulheres em escolher a posição do parto: de cócoras, na água ou deitada (CANCIAN, 2015).

No início de janeiro de 2015, o Ministério da Saúde (MS) e a Agência Nacional de Saúde Suplementar (ANS) que regula os planos de saúde privados no país, publicaram uma resolução com o objetivo de reduzir o número de partos cirúrgicos considerados desnecessários. Essas medidas, que devem começar a valer no segundo semestre, exigirão que os médicos justifiquem de maneira mais rigorosa e detalhada os motivos que levaram à escolha da cirurgia para o nascimento da criança, caso contrário, podem deixar de receber pelo trabalho. É um esforço, considerado apenas paliativo, para tentar diminuir os índices absurdamente elevados de partos cirúrgicos feitos no Brasil, em especial no setor privado de saúde (BRASIL, 2014; AGENCIA NACIONAL DE SAÚDE SUPLEMENTAR, 2014; CANCIAN, 2015).

Com essa nova resolução da ANS (2015), as pacientes terão a carteira da gestante, um documento que deverá ser apresentado em todos os estabelecimentos de saúde que utilizar durante a gestação e na maternidade quando for admitida em trabalho de parto. Nessa carteira constará todo o histórico do pré-natal, com resultados de exames e detalhes sobre a evolução da gravidez para que a ela possa ser atendida por qualquer profissional de saúde (BRASIL, 2015)

Entretanto, é preciso destacar que, ainda, há muito para se fazer a fim de garantir um parto seguro, digno e respeitoso para todas as mulheres como preconiza a OMS. O direito à escolha informada deve ser respeitado pelos profissionais que prestam atendimento a esta clientela, e cabe a esse profissional dar-lhes acesso às informações baseadas em evidências científicas, permitindo que essa mulher tenha instrumentos necessários para escolher o tipo de parto que mais lhe agrada (MEDEIROS; SANTOS; SILVA, 2008).

\subsection{Casas de Parto e a valorização do parto por um processo natural}

A criação das Casas de Parto para o atendimento das parturientes não acometidas por doenças clínicas e ou obstétricas foi proposta porque se acreditou que esta seria uma alternativa possível à humanização da assistência nesse âmbito (HOGA, 2004). Nessa perspectiva, as Casas de Parto visam valorizar o fenômeno do parto e nascimento em sua essência fisiobiológica como um processo natural e na sua dimensão social. Funciona como uma unidade autônoma, dispondo de recursos materiais e humanos compatíveis para prestar assistência de qualidade às gestantes, parturiente e aos nascituros. Geralmente, é construída em convênio com unidades de referências, próxima ao hospital ou maternidade e, constituída por equipe mínima: um enfermeiro obstetra, um auxiliar de enfermagem, um auxiliar de serviços gerais e um motorista de ambulância (HADDAD, 2004).

Diante dos desafios a serem vencidos, referentes ao parto humanizado, as Casas de Parto apontam como uma alternativa viável que proporciona uma assistência humanizada à mulher no ciclo gravídico-puerperal. Trata-se de uma estrutura institucional menor que preconiza a atuação autônoma do enfermeiro obstétrico, ou seja: facilita a integração da equipe de trabalho, possibilita a colaboração e respeito mútuo entre o grupo profissional e os clientes. A atuação do profissional de enfermagem torna-se essencial e de extrema importância, pois deve pautar, por essência o cuidar, e é nesse profissional que encontra-se a raiz dessa assistência humanizada, voltada primeiramente ao ser humano (HOGA, 2004; BOFF, 2003).

Para o Ministério da Saúde (2000), dois aspectos são fundamentais na humanização: o primeiro diz res- 
peito à conviç̧ão de que é dever das unidades de saúde receber com dignidade a mulher, seus familiares e o recém-nascido. $\mathrm{O}$ segundo se refere à adoção de medidas e procedimentos sabidamente benéficos para o acompanhamento do parto e do nascimento, evitar práticas intervencionistas desnecessárias, tradicionalmente realizadas, e que não beneficiam a mulher nem o recém-nascido e que, com frequência, acarretam maiores riscos para ambos, e a Casa de Parto destina-se a receber com dignidade a mulher, com uma atitude ética e solidária por parte dos profissionais de saúde que ali atuam.

Infelizmente, em todo o país são apenas $14 \mathrm{Ca}$ sas de Parto e, mesmo assim, são bastante criticadas pelo Conselho de Medicina, que afirma que para ter um parto seguro é necessário estar em ambiente hospitalar e supervisionado por um médico obstetra, contrariando o paradigma das Casas que afirma ser uma unidade de saúde destinada à assistência humanizada e de qualidade ao parto fisiológico que devolvem a parturiente com gestação de baixo risco o protagonismo do parto, confrontando e afirmando que é necessário uma transformação da cultura predominante nas instituições que prestam assistência ao parto e nascimento de forma totalmente intervencionista (BOFF, 2003; CANCIAN, 2015).

Nesse sentido, a Casa de Parto é humanizar, é devolver a voz da parturiente, é permitir que ela seja consciente da sua posição como figura central no processo, fazendo valer seus direitos, sua autonomia e seu valor pessoal. E cabe ao profissional que almeja uma atuação humanista promover o envolvimento efetivo da parturiente nesse processo como sujeito ativo e consciente dos seus direitos (MARTINS et al., 2005).

\section{Considerações finais}

A maioria dos estudos revelaram a preferência das gestantes pela via vaginal contrastando com os altos índices de cesáreas registradas atualmente no Brasil. Essa mudança drástica de opinião pode ser explicada pelo processo de vivência do parto doloroso, pelo alto índice lucrativo das instituições de saúde no parto cirúrgico, pela desvalorização dos demais profissionais, pela falta de orientação das gestantes sobre sua autonomia, pelo desinteresse dos médicos pelo parto normal com uma conduta totalmente intervencionista e pela chance da esterilização.

Nesse mesmo contexto de parturição, verificou-se pela Agência Nacional de Saúde (ANS) que o conhecimento da gestante sobre o tema ainda é bastante fragilizado, levando-a se submeter a todo procedimento obstétrico sem questionamentos, e essa aceitação ignaro e submissa é intensificada pelo poder público, pois a visão de que o parto normal traz experiências dolorosas e insuportáveis ainda está arraigada na população, além de existir vários mitos relacionados a essa via de parto, como a elasticidade vaginal, a redução do libido e a inadequação sexual após o parto normal. Por vezes, o próprio profissional de saúde acentua esse fato, visto que não se prontifica a desmistificar o parto vaginal e de trazer para a gestante esclarecimentos sobre todo o processo de analgesia não farmacológico tais como o apoio contínuo em ambiência da maternidade, a liberdade de movimentação e adoção de posições de preferência da mulher com o auxílio, ou não, dos instrumentos de fisioterapia, e o acesso à água que proporciona a redução significativa da sensibilidade a dor conforme propostas do Ministério da Saúde.

Essa omissão de informação por parte da equipe de saúde nos leva a concluir que não está sendo estabelecido um vínculo adequado entre a gestante e seu médico assistente a ponto de elucidar todas as dúvidas e expectativas das gestantes. Esse aspecto tem se intensificado por um processo histórico educacional curativista e intervencionista, que desvaloriza os demais profissionais da área obstétrica, levando o médico à posição de detentor do poder de decisão, gerando uma invasão da privacidade da parturiente com a utilização de procedimentos desnecessários e uma quebra total da vontade da gestante. Essa situação é contrastada pela Resolução CFM No 2.144/2016 que garante ao casal, em particular a gestante o direito de decidir, em situações eletivas, sobre a via de parto que seus filhos nascerão, desde que os pais sejam esclarecidos com precisas e claras sobre os dois tipos de parto, e seus respectivos riscos e benefícios, garantindo a autonomia do médico, da parturiente e a segurança da mãe e do bebê.

Outro agravante a esse processo de decisão é a questão financeira, um profissional recebe quase a mesma coisa para fazer uma cesárea, e a imprevisibilidade do parto normal, que pode passar de 12 horas de trabalho de parto, leva esse profissional a opinar pela cesárea que dura no máximo 3 horas, essa baixa remuneração com um elevado período de trabalho chancela o desejo pela cirurgia já que o profissional poderá ganhar mais, em menos tempo. Essa circunstância vem gerando uma 
indústria de cesáreas, em que a maioria dos partos hoje realizados não são praticados de forma emergencial, mas de maneira programada marcadas conforme agenda do médico e da paciente. Esse processo financeiro se fortalece com a esterilização cirúrgica no qual o desejo da laqueadura agrega valores no somatório final do honorário aumentando, ainda mais, a incidência de cesáreas.

Frente a isso, destaca-se a responsabilidade da enfermagem em atuar na reeducação das próprias pacientes explicando a elas questões inerentes ao parto natural como seu processo de humanização e todos os métodos para alívio das dores, concentrando sua ação na mudança de atitude e informação da gestante, pois, ao oferecer conhecimento as parturientes, elas poderão opinar com segurança sobre a melhor via de parto para elas.

\section{Referências}

AGENCIA NACIONAL DE SAÚDE SUPLEMENTAR. Ministério da Saúde e ANS criam normas para reduzir cesariana. Rio de Janeiro: ANS, 2014. Disponível em: <http://www.ans.gov.br/aans/noticias-ans/sobre-a-ans/ 2614-coletiva?.pdf>. Acesso em: 04 abr. 2015.

AGENCIA NACIONAL DE SAÚDE SUPLEMENTAR. Taxas de partos cesáreos por operadora de plano de saúde. Rio de Janeiro: ANS, 2013. Disponível em: <http:// www.ans.gov.br/planos-de-saude-e-operadoras/informacoes-e-avaliacoes-de-operadoras/taxas-de-partos-cesareos-por-operadora-de-plano-de-saude?.pdf $>$. Acesso em: 04 abr. 2015.

ALMEIDA, N. A. M. et al. A dor do parto na literatura científica da Enfermagem e áreas correlatas indexada entre 1980 - 2007. Revista Eletrônica de Enfermagem, Goiás, v. 10, n. 4, p. 1114-1123, dez. 2008.

ALMEIDA, N. A. M. et al. Utilização de técnicas de respiração e relaxamento para alívio de dor e ansiedade no processo de parturição. Revista Latino-Americana de Enfermagem, São Paulo, v. 13, n. 1, p. 52-58, jan./fev. 2005. doi: 10.1590/S0104-1169200500010000.

BARBA, M. D.; BARIFOUSE, R. Desvalorização de parto normal torna Brasil líder mundial de cesáreas. São Paulo, 2015. Disponível em: <http://www.bbc.co.uk/ portuguese/noticias/2014/04/140411_cesareas_principal_mdb_rb>. Acesso em: 06 abr. 2015.
BARBOSA, G. P. et al. Parto cesáreo: quem o deseja? em quais circunstâncias? Cadernos de Saúde Pública, Rio de Janeiro, v. 19, n. 6, p. 1611-1620, nov./dez. 2003. doi: 10.1590/S0102-311X2003000600006.

BEHAGUE. D. P.; VICTORA, C. G.; BARROS, F. C. Consumer demand for caesarean sections in Brazil: informed decision making, patient choice, or social inequality? a population based birth cohort study linking ethnographicand epidemiological methods. BMJ, London, v. 324, n. 7343, p. 942-948, abr. 2002. doi: 10.1136/ bmj.324.7343.942.

BERNARDO, W. M.; NOBRE, M. R. C.; JATENE, F. B. A prática clínica baseada em evidências: parte II: buscando as evidências em fontes de informação. Revista da Associação Médica Brasileira, São Paulo, v. 44, n. 6, p. 403-409, nov./dez. 2004. doi: 10.1590/S0104-42302004000100045.

BOFF, L. Saber cuidar: ética do humano-compaixão pela terra. Rio Grande do Sul: Vozes, 2003.

BRASIL. Ministério da Saúde. Humanização do parto e do nascimento. Brasília: MS, 2014.

BRASIL. Ministério da Saúde. Manual prático para implementação da Rede Cegonha. Brasília: MS, 2011.

BRASIL. Ministério da Saúde. Parto, aborto e puerpério: assistência humanizada à mulher. Brasília: MS, 2001.

BRASIL. Ministério da Saúde. Pré-natal e puerpério: atenção qualificada e humanizada: manual técnico. Brasília: MS, 2005.

BRUGGEMANN, O. M. A. Melodia da humanização: reflexões sobre o cuidado no processo de nascimento. Santa Catarina: Cidade Futura, 2001.

CANCIAN, N. Médicos serão controlados e terão que justificar cesáreas. Brasília. 2015. Disponível em: <http:// www1.folha.uol.com.br/cotidiano/2015/01/1571169-planos-de-saudes-terao-que-informar-taxa-de-cesareas-de-medico-e-hospital.shtml>. Acesso em: 7 abr. 2015.

CARVALHO, M. L. O renascimento do parto e do amor. Revista Estudos Feministas, Santa Catarina, v. 10, n. 2, p. 521-523, jul./dez. 2002. doi: 10.1590/S0104026X2002000200022. 
CASTRO, J. C.; CLAPIS, M. J. Parto humanizado na percepção das enfermeiras obstétricas envolvidas com a assistência ao parto. Revista Latino-Americana de Enfermagem, São Paulo, v. 13, n. 6, p. 960-967, nov./dez. 2005. doi: 10.1590/S0104-11692005000600007.

CHIORO, A.; OLIVEIRA, M. Para mudar a cultura de cesarianas no país. São Paulo, 2015. Disponível em: <http:// www1.folha.uol.com.br/opiniao/2015/02/1586501-arthur-chioro-e-martha-oliveira-para-mudar-a-cultura-de-cesarianas.shtml>. Acesso em: 12 abr. 2015.

CRIZÓSTOMO, C. D.; NERY, I. S.; LUZ, M. H. B. A vivência de mulheres no parto domiciliar e hospitalar. Escola Anna Nery, Rio de Janeiro, v. 11, n. 1, p. 98-104, mar. 2007. doi: 10.1590/S1414-81452007000100014.

DAVIM, R. M. B.; MENEZES, R. M. P. Assistência ao parto normal no domicílio. Revista Latino-Americana de Enfermagem, São Paulo, v. 9, n. 6, p. 62-68, nov. 2001. doi: 10.1590/S0104-11692001000600011.

DIAS, I. M. V.; SANTOS, R. S. Método, história de vida e sua aplicabilidade no campo da enfermagem. Escola Anna Nery, Rio de Janeiro, v. 9, n. 2, p. 278-286, ago. 2005.

DIAS, M. A. B. et al. Trajetória das trajetória de mulheres na definição pelo parto cesáreo: estudo de caso em duas unidades do Sistema de saúde suplementar do Estado do Rio de Janeiro. Ciência e Saúde Coletiva, Rio de Janeiro, v. 13, n. 5, p. 1521-1534. set./out. 2008. doi: 10.1590/ S1413-81232008000500017.

DINIZ, S. G.; CHACHAN, A. Dossiê humanização do parto. São Paulo: Rede Feminista de Saúde, 2002.

DINIZ, S. G.; DUARTE, A. C. Parto normal ou cesárea? O que toda mulher deve saber e todo homem também. São Paulo: UNESP, 2004.

DOMINGUES, R. M. S. M. et al. Processo de decisão pelo tipo de parto no Brasil: da preferência inicial das mulheres à via de parto final. Cadernos de Saúde Pública, Rio de Janeiro, v. 30, p. S101-S116. ago. 2014. supl. 1. doi: 10.1590/0102-311X00105113.

ESPINDULA, T. C. A. S. Judicialização da medicina no acesso a medicamentos: reflexões bioéticas. Revista Bioética, Brasília, v. 21, n. 3, p. 438-447, out. 2013.
FAISAL-CURY, A.; MENEZES, P. R. Fatores associados à preferência por cesariana. Revista de Saúde Pública, São Paulo, v. 40, n. 2, p. 226-232, abr. 2006. doi: 10.1590/ S0034-8910200600020000.

FAUNDES A. et al. Opinião de mulheres e médicos brasileiros sobre a preferência pela via de parto. Revista de Saúde Pública, São Paulo, v. 38, n. 4, p. 488-494, ago. 2004. doi: 10.1590/S0034-89102004000400002.

FERRARI, J. À autonomia da gestante e o direito pela cesariana a pedido: à escolha da via de parto deve ser um direito das mulheres e não uma imposição da burocracia estatal, cientificamente inconsistente. Paraná: CRV, 2014.

FLOYD, D. R. Del medico al sanador. Buenos Aires: Creavida, 2004.

FREITAS, P. F.; SAKAE, T. M.; JACOMINO, M. E. M. L. P. Fatores médicos e não médicos associados às taxas de cesariana em um hospital universitário no Sul do Brasil. Cadernos de Saúde Pública, Rio de Janeiro, v. 24, n. 5, p. 10511061, maio 2008. doi: 10.1590/S0102-311X2008000500012.

GAMBLE, J. A.; CREEDY, D. K. Women's request for a cesarean section: a critique of the literature. Birth, Malden, v. 27, n. 4, p. 256-263, dez. 2000. doi: 10.1046/j. 1523-536x.2000.00256.x.

HADDAD, S. M. T.; CECECATTI, J. G. Estratégias dirigidas aos profissionais para a redução das cesáreas desnecessárias no Brasil. Revista Brasileira de Ginecologia Obstétrica, Rio de Janeiro, v. 33, n. 5, p. 252262, maio 2011. doi: 10.1590/S0100-72032011000500008.

HOFBERG, K.; BROCKINGTON, I. F. Tokophobia: an unreasoning dread of childbirth. The British Journal of Psychiatry, London, v. 176, n. 1, p. 83-85, jan. 2000. doi: 10.1192/bjp.176.1.83.

HOGA, L. A. K. Casas de Parto: simbologia e princípios assistenciais. Revista Brasileira de Enfermagem, Brasília, v. 57, n. 5, p. 537-540, set./out. 2004. doi: 10.1590/ S0034-71672004000500004.

IORRA, M. R. K. et al. Aspectos relacionados à preferência pela via de parto em um hospital universitário. Revista da Associação Médica do Rio Grade do Sul, Porto Alegre, v. 55, n. 3, p. 260-268, jul./set. 2011. 
JONES, R. Memórias de um homem de vidro: reminiscências de um obstetra humanista. Rio Grande do Sul: Idéias a Granel, 2004.

LEAL, M. C. Nascer no Brasil: a mãe sabe como parir e o bebê sabe como e quando nascer. Rio de Janeiro: FIOCRUZ, 2014. Disponível em: <http://www.ensp.fiocruz. br/portal-enps/informe/site/arquivos/anexos/nascerweb. pdf>. Acesso em: 16 abr. 2015.

LEE, S. I.; KHANG, Y. R.; LEE, M. S. Women's attitudes toward mode of delivery in South Korea: society with high cesarean section rates. Birth, Malden, v. 31, n. 2, p. 116118, jun. 2004. doi: 10.1111/j.0730-7659.2004.00288.x.

LESSA, H. F. Parto em casa: vivências de mulheres. 2003. 97 f. Dissertação (Mestrado) - Programa de Pós-graduação em Enfermagem, Universidade do Estado do Rio de Janeiro, Rio de Janeiro, 2003.

LEGUIZAMON JUNIOR, T.; STEFFANI, J. A.; BONAMIGO, E. L. Escolha da via de parto: expectativa de gestantes e obstetras. Revista Bioética, Brasília, v. 21, n. 3, p. 509-517, set./dez. 2013.

LIMA, T. C. S; MIOTO, R. C. T. Procedimentos metodológicos na construção do conhecimento científico: a pesquisa bibliográfica. Revista Katálysis, Florianópolis, v. 10, n. especial, p. 37-45, abr. 2007. doi: 10.1590/S141449802007000300004.

LOPES, R. C. S. et al. O antes e o depois: expectativas e experiências de mães sobre o parto. Psicologia: Reflexão e Crítica, Rio Grande do Sul, v. 18, n. 2, p. 247-254. maio/ ago. 2005. doi: 10.1590/S0102-79722005000200013.

MALDONADO, M. T. Psicologia da gravidez, parto e puerpério. 16. ed. São Paulo: Saraiva, 2002.

MARTINS, C. A. et al. Casas de parto: sua importância na humanização da assistência ao parto e nascimento. Revista Eletrônica de Enfermagem, Goiás, v. 7, n. 3, p. 360-365, dez. 2005. doi: 10.5216/ree.v7i3.891.

MEDEIROS, R. M. K.; SANTOS, I. M. M.; SILVA, L. R. A escolha pelo parto domiciliar: história de vida de mulheres que vivenciaram esta experiência. Escola Anna Nery, Rio de Janeiro, v. 12, n. 4, p. 765-772, dez. 2008.
MEDINA, E. T. Tecnologias de cuidado de enfermagem obstétrica e seus efeitos sobre o trabalho de parto: um estudo exploratório. 2003. 75 f. Dissertação (Mestrado) - Programa de Pós-Graduação em Enfermagem, Universidade do Estado do Rio de Janeiro, Rio de Janeiro, 2003.

MELO, C. R. M. Parto: mitos construídos, mitos em construção. São Paulo: EDUSC, 2003.

MORAES, M. S.; GOLDENBERG, P. Cesáreas: um perfil epidêmico. Cadernos de Saúde Pública, Rio de Janeiro, v. 17, n. 3, p. 509-519. maio/jul. 2001. doi: 10.1590/S0102$311 \mathrm{X} 2001000300007$.

SCHMIDT, E. B.; PICCOLOTO, N. M.; MULLER, M. C. Depressão pós-parto: fatores de risco e repercussões no desenvolvimento infantile. Psico - USF, Rio Grande do Sul, v. 10, n. 1, p. 61-68, jan./jun. 2005. doi: 10.1590/ S1413-82712005000100008.

OLIVEIRA, S. M. J. V. et al. Tipo de parto: expectativas das mulheres. Revista Latino-Americana de Enfermagem, São Paulo, v. 10, n. 5, p. 667-674, set./out. 2002. doi: 10.1590/S0104-11692002000500007.

PANG, M. W. et al. Impact of first childbirth on changes in women's preference for mode of delivery: follow-up of a longitudinal observartional study. Birth, Malden, v. 35, n. 2, p. 121-128, jun. 2008. doi: 10.1111/j.1523-536X.2008.00225.x.

POTTER, J. E. et al. Unwanted caesarean sections among public and private patients in Brazil: prospective study. BMJ, London, v. 323, n. 7322, p. 1155-1158, nov. 2001. doi: 10.1136/bmj.323.7322.1155.

RATTNER, D. Humanização na atenção a nascimentos e partos: breve referencial teórico. Interface: comunicação, saúde, educação, São Paulo, v. 13, p. S595-S602, jan. 2009. supl. 1. doi: 10.1590/S1414-32832009000500011.

REZENDE, J. F. Rezende obstetrícia. 11. ed. Rio de Janeiro: Guanabara Koogan, 2010.

ROTHER, E. T. Revisão sistemática X revisão narrativa. Acta Paulista de Enfermagem, São Paulo, v. 20, n. 2, p. 5-6, jun. 2007. doi: 10.1590/S0103-21002007000200001.

SANTOS, F. L. História da medicina no Brasil. 2. ed. São Paulo: Brasiliense, 1947. 
SEIBERT, S. L. et al. Medicalização x humanização: o cuidado ao parto na história. Revista de Enfermagem da UERJ, Rio de Janeiro, v. 13, n. 2, p. 245-251, maio/ago. 2005.

SILVEIRA, M. F. et al. Aumento da prematuridade no Brasil: revisão de estudos de base populacional. Revista de Saúde Pública, São Paulo, v. 42, n. 5, 957-964, out. 2008. doi: 10.1590/S0034-89102008000500023.

SOUZA, H. R. A arte de nascer em casa: um olhar antropológico sobre a ética, a estética e a sociabilidade no parto domiciliar contemporâneo. 2005. 155 f. Dissertação (Mestrado) - Programa de Pós-graduação em Antropologia Social, Universidade Federal de Santa Catarina, Santa Catarina, 2005.

TEDESCO, R. P. et al. Fatores determinantes para as expectativas de primigestas acerca da via de parto. Revista Brasileira de Ginecologia Obstétrica, Rio de Janeiro, v. 26, n. 10, p. 791-798, nov./dez. 2004. doi: 10.1590/S010072032004001000006 .

TEIXEIRA, N. Z.; PEREIRA, W. R. Parto hospitalar: experiências de mulheres da periferia de Cuiabá-MT. Revista Brasileira de Enfermagem, Distrito Federal, v. 59, n. 6, p. 740-744, nov./dez. 2006. doi: 10.1590/S003471672006000600004 .
TORNQUIST, C. S. Paradoxos da humanização em uma maternidade no Brasil. Cadernos de Saúde Pública, Rio de Janeiro, v. 19, n. 2, p. 419 - 427, jan. 2003. doi: 10.1590/ S0102-311X2003000800023.

TRINDADE, Etelvino. Governo anuncia medidas para incentivar o parto normal. Rio de Janeiro: Febrasgo, 2015. Disponível em: <http://www.febrasgo.org.br/site $/$ ? $=8654>$. Acesso em: 04 abr. 2015.

CANCIAN, Natalia. Cesáreas passam de 90\% em metade das operadoras. Folha de São Paulo, São Paulo, 19 nov. 2015. Disponível em: <http://wwwl.folha.uol.com.br/cotidiano/2015/01/1576493-cesareas-passam-de-90-em-metade-das-operadoras-de-saude.shtml >. Acesso em: 06 abr. 2015.

VICTORA, C. G. et al. Maternal and child health in Brazil: progress and challenges. The Lancet, United Kingdom, v. 377, n. 9780 , p. 32-46, maio, 2011. doi: 10.1016/ S0140-6736(11)60138-4.

VIEIRA, E. M. A medicalização do corpo feminino. Rio de Janeiro: Fiocruz, 2002. 